\title{
Three Phases of Phagocyte Contribution to Resistance against Listeria monocytogenes
}

\author{
By MASAO MITSUYAMA, KENJI TAKEYA, KIKUO NOMOTO \\ AND SHOICHI SHIMOTORI \\ Departments of Microbiology and Immunology, School of Medicine, Kyushu University, \\ Higashi-ku, Fukuoka, 812 Japan
}

(Received 13 September 1977; revised 12 January 1978)

\begin{abstract}
The contribution of phagocytes to protection against Listeria monocytogenes was analysed in outbred ddN mice. Most of the bacteria injected intravenously at a dose of $3 \times 10^{3}$ to $4 \times 10^{3}$ were trapped in the liver within $10 \mathrm{~min}$. There was a transient 10 -fold decrease in the number of bacteria by $6 \mathrm{~h}$. Anti-listeria activity in the initial phase was resistant to $\mathrm{X}$-irradiation but was inhibited by carrageenan, and was not influenced by immunization. The protection in this very early stage of infection seemed to be attributable to the function of fixed macrophages. Viable bacteria in the organs increased progressively but slowly from $6 \mathrm{~h}$ to $72 \mathrm{~h}$ to reach maximum numbers. Bacterial growth during this period was markedly enhanced by X-irradiation or treatment with carrageenan. Accumulation of free phagocytes seemed to suppress the bacterial growth in this phase. The number of bacteria began to decrease from day 4 and became undetectable by day 9 . The suppressive effect on bacterial growth in this last phase may be dependent on immunologically activated macrophages and was reversed by X-irradiation and carrageenan. The course of local infection was similar to that of systemic infection except for the lack of initial decrease. We conclude that the course of infection with $L$. monocytogenes can be divided into three phases with regard to the roles of phagocytes in resistance.
\end{abstract}

\section{INTRODUCTION}

It is well known that after intravenous inoculation of Listeria monocytogenes into normal mice, the number of live bacteria per organ increases during the first $3 \mathrm{~d}$ of infection but begins to decrease from day 4 (Mackaness, 1962). Such protection has been presumed to depend primarily upon macrophages activated by sensitized lymphocytes. Therefore, a fulminating course of infection would be expected to occur in athymic nude mice. However, nude mice showed a persistent form of infection (Emmerling, Finger \& Bockemühl, 1975; Takeya et al., 1977). During the first $3 \mathrm{~d}$ of infection, the number of bacteria in the liver or spleen was smaller in nude mice than in normal littermates. Takeya et al. (1977) showed that the number of bacteria after $72 \mathrm{~h}$ of infection was strikingly increased by whole body irradiation with a lethal dose $(900 \mathrm{R})$, or by administration of blocking agents of the reticuloendothelial system. Free phagocytes appear to suppress a fulminating bacterial growth, especially at an early stage of infection. Activated macrophages appear to be required for complete elimination of bacteria at a later stage of infection.

The present study was undertaken to analyse further the contribution of phagocytes to resistance at different stages of listeria infection. The course of infection appears to be separated into three phases with regard to the contribution of phagocytes to the resistance. 


\section{METHODS}

Animals. Female mice of an outbred ddN strain were obtained from the Breeding Unit of Experimental Animals, Kyushu University. Mice were used for experiments at 8 to 12 weeks of age.

Micro-organism. Listeria monocytogenes (EGD) was kindly donated by Dr Ishibashi, Research Institute for Diseases of the Chest, School of Medicine, Kyushu University. The bacteria were maintained by serial passage in outbred $\mathrm{CF}_{1}$ mice and passed through ddN mice for a few generations before use in this study. Fresh isolates were obtained from spleens, grown once on Tryptic Soy Agar medium (Difco) and used for infection. The $\mathrm{LD}_{50}$ by the intravenous route of infection was approximately $8 \times 10^{4}$ viable bacteria.

Determination of bacterial growth. Mice were inoculated intravenously with $3 \times 10^{3}$ to $4 \times 10^{3}$ or $1 \times 10^{6}$ viable bacteria in Hanks' balanced salt solution. At various times after inoculation, they were bled by cutting the femoral artery, and their livers and spleens were removed. Individual organs were homogenized separately in $10 \mathrm{ml}$ phosphate-buffered saline (PBS) with Teflon homogenizers. The homogenized suspensions were diluted serially 10 -fold with PBS and $0.1 \mathrm{ml}$ of each dilution was spread on nutrient agar containing $0.3 \%(\mathrm{w} / \mathrm{v})$ glucose. Three plates were prepared for each dilution ot each specimen. Colonies were counted after incubation for $20 \mathrm{~h}$ at $37^{\circ} \mathrm{C}$. To observe bacterial growth in a local infection, bacterial suspensions were inoculated intramuscularly into the middle of the right thigh. The whole mass of the muscle of an infected thigh was removed and treated in the same way as described for the estimation of bacterial growth in the liver and spleen.

Immunization. Mice were inoculated intravenously with $3 \times 10^{3}$ to $4 \times 10^{3}$ viable bacteria and used as immunized hosts $14 \mathrm{~d}$ later. Preliminary experiments had shown that the degree of acquired immunity was higher at $14 \mathrm{~d}$ than at 7 or $21 \mathrm{~d}$ after infection.

$X$-irradiation. Mice were exposed to 900 or $1000 \mathrm{R}$ of whole body X-irradiation and infected $3 \mathrm{~d}$ later. The radiation was delivered from a Shimadzu $250 \mathrm{kV}$ machine operating at $200 \mathrm{kV}$ with $0.3 \mathrm{~mm} \mathrm{Cu}$ and $1 \mathrm{~mm}$ Al filtration at $100 \mathrm{~cm}$ from the target focus. In order to protect the liver from damage by irradiation, the lower chest and upper abdomen were covered with two layers of a lead plate $0.9 \mathrm{~mm}$ thick and $12 \mathrm{~mm}$ wide. Approximately $95 \%$ of the X-ray dose was estimated to be blocked by this shielding method.

Carrageenan. Carrageenan type II (Sigma) was dissolved in distilled water (to give $5 \mathrm{mg} \mathrm{ml}^{-1}$ ) and injected intraperitoneally at a dose of $200 \mathrm{mg} \mathrm{kg}^{-1} 24 \mathrm{~h}$ before infection.

\section{RESULTS}

\section{Time course of bacterial growth after intravenous inoculation in normal mice}

The time course of $L$. monocytogenes infection in normal mice is shown in Fig. 1. Approximately $90 \%$ of the inoculum was recovered from the liver 10 min after inoculation. The number of bacteria decreased 10 -fold by $6 \mathrm{~h}$ and increased again to reach a maximum at 2 to $3 \mathrm{~d}$. The number decreased gradually from day 4 to become undetectable by day 9 . In the spleen, the number of live bacteria taken up in $10 \mathrm{~min}$ was smaller than in the liver. The number increased rapidly without the early transient reduction observed in the liver. The decrease began from day 4 in the spleen as well as in the liver. Preliminary experiments showed that the blood (approximately $1 \mathrm{ml}$ ) contained less than $1 \%$ of the inoculum after $10 \mathrm{~min}$, so the bacterial counts in the organ were regarded as trapped bacteria.

The course of infection in the liver was divided tentatively into three phases: the first phase up to $6 \mathrm{~h}$, the second phase up to day 3 and the third phase from day 4 to day 9 .

\section{Effect of $X$-irradiation on the course of infection}

To analyse more precisely the first phase in the liver, a large dose (over $10 \mathrm{LD}_{50}$ ) of inoculum was used. Viable $L$. monocytogenes $\left(10^{6}\right)$ were injected intravenously into 1000 R-irradiated mice and non-irradiated controls. The trapping of bacteria by $10 \mathrm{~min}$ and the progressive decrease from $10 \mathrm{~min}$ to $6 \mathrm{~h}$ showed similar patterns in both groups (Fig. $2 a$ ).

The course of infection was plotted daily after inoculation of $2 \times 10^{3}$ bacteria into irradiated mice. In the liver, irradiation enhanced bacterial growth slightly on day 1 , and markedly on days 2 and 3. Shielding of the liver with lead plates did not prevent progressive bacterial growth by day 3 (Fig. $2 b$ ). In the spleen, bacterial growth was enhanced appreciably by irradiation. 


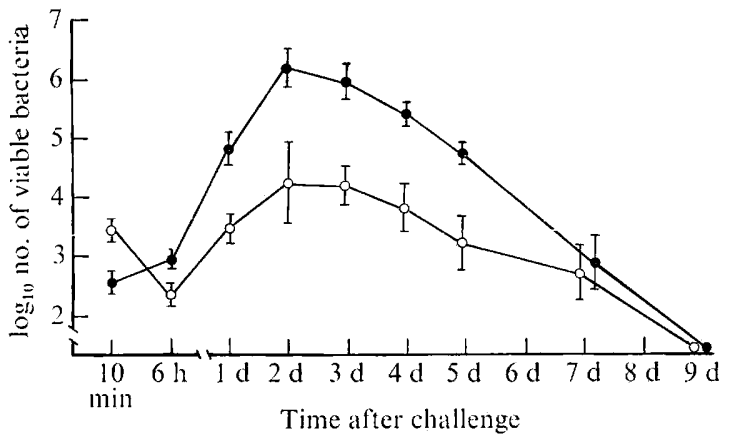

Fig. 1. Time course of bacterial growth in the liver $(O)$ and spleen $(\bullet)$ after intravenous inoculation of $3.2 \times 10^{3}$ L. monocytogenes into normal mice. Each point and bar indicates the mean result for five animals \pm S.E.M.

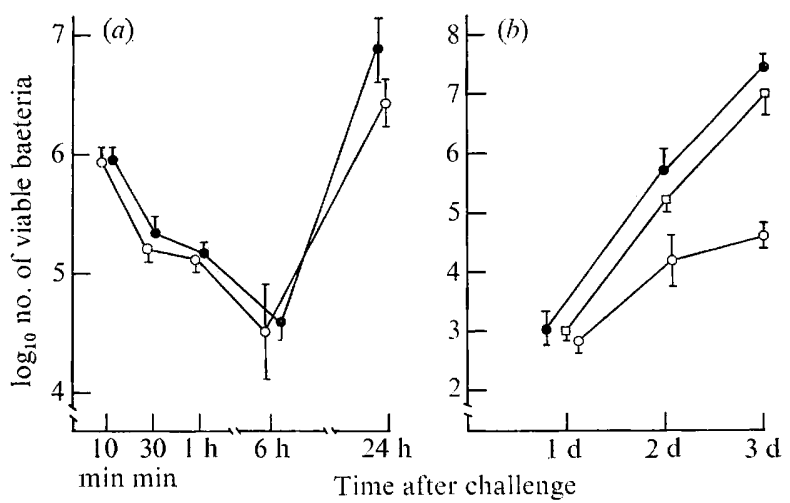

Fig. 2. Effect of 1000 R-irradiation on liver counts at (a) a very early stage of infection after intravenous inoculation of $10^{6} \mathrm{~L}$. monocytogenes and $(b)$ an early stage of infection after inoculation of $2 \times 10^{3}$ bacteria: $\bigcirc$, control mice; $\bullet$, irradiated mice; $\square$, mice irradiated with the liver shielded. Each point and bar indicates the mean result for five animals \pm S.E.M.

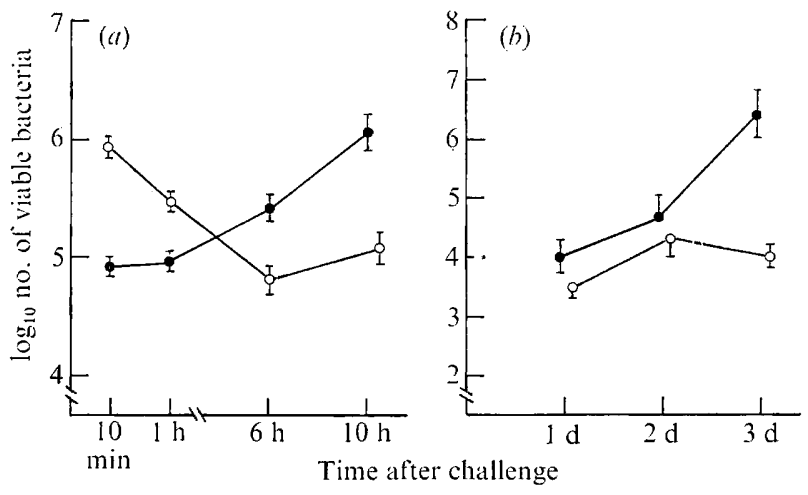

Fig. 3. Effect of carrageenan on liver counts at $(a)$ a very early stage of infection after intravenous inoculation of $10^{6} \mathrm{~L}$. monocytogenes and $(b)$ an early stage of infection after inoculation of $4.1 \times 10^{3}$ bacteria: $O$, control mice; $\bullet$, mice treated with carrageenan. Each point and bar indicates the mean result for five animals \pm S.E.M. 


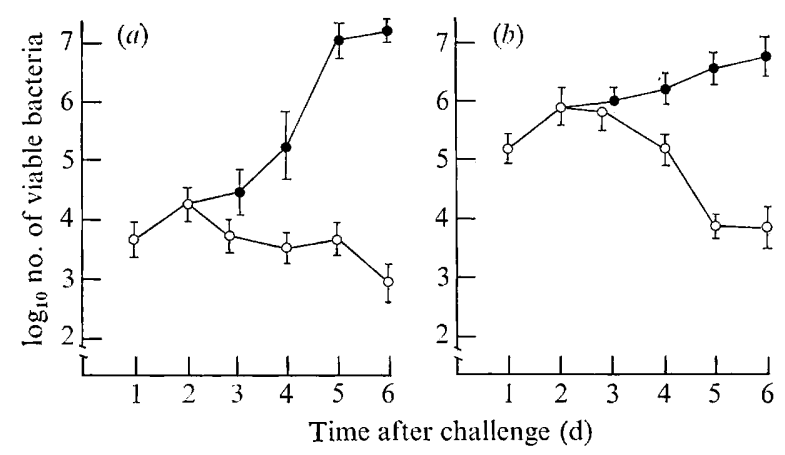

Fig. 4. Enhancement by treatment with carrageenan of bacterial growth in $(a)$ the liver and $(b)$ the spleen after intravenous inoculation of $3.5 \times 10^{3} \mathrm{~L}$. monocytogenes: $\bigcirc$, control mice; $\bullet$, mice treated with carrageenan $60 \mathrm{~h}$ after challenge. Each point and bar indicates the mean result for five animals \pm S.E.M.

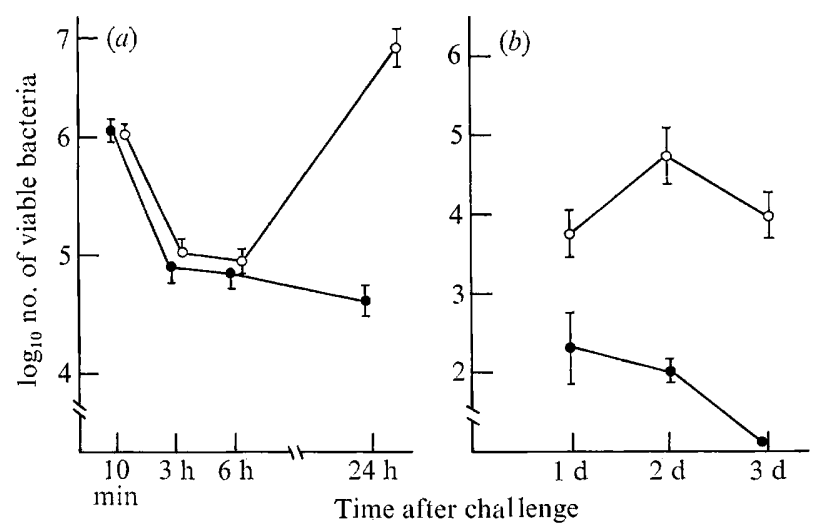

Fig. 5. Continuous decrease in the number of bacteria in the liver of immunized mice after intravenous re-challenge with $(a) 10^{6}$ or $(b) 3 \times 10^{3}$ L. monocytogenes: $\bigcirc$, control mice; $\bullet$, immunized mice. Each point and bar indicates the mean result for five animals \pm S.E.M.

\section{Effect of carrageenan on the course of infection at various stages of infection}

Mice were inoculated with $10^{6}$ L. monocytogenes $24 \mathrm{~h}$ after treatment with carrageenan. The number of live bacteria trapped in the liver by $10 \mathrm{~min}$ was reduced 10 -fold compared with the number in non-treated controls. Moreover, the number of bacteria increased gradually without the reduction observed in controls (Fig. $3 a$ ). Figure $3(b)$ shows a growth curve of $L$. monocytogenes in carrageenan-treated mice after challenge with $4 \cdot 1 \times 10^{3}$ bacteria. Administration of carrageenan enhanced bacterial growth slightly on days 1 and 2 , and markedly on day 3 .

When carrageenan was injected intraperitoneally into normal mice $60 \mathrm{~h}$ after challenge with $3.5 \times 10^{3}$ bacteria, the number of live bacteria in the liver began to increase (Fig. $4 a$ ). In the spleen, bacterial counts increased slightly from day 3 to 6 (Fig. $4 b$ ).

\section{Effect of host treatments on bacterial growth in immunized mice}

To examine the pattern of bacterial elimination in immunized mice, $10^{6} \mathrm{~L}$. monocytogenes were inoculated into immunized mice and non-immunized controls. The same numbers of bacteria were trapped in the liver of both groups by $10 \mathrm{~min}$ and the numbers decreased from $10 \mathrm{~min}$ to $6 \mathrm{~h}$ in both groups in a similar fashion. Thereafter, the number of bacteria in 


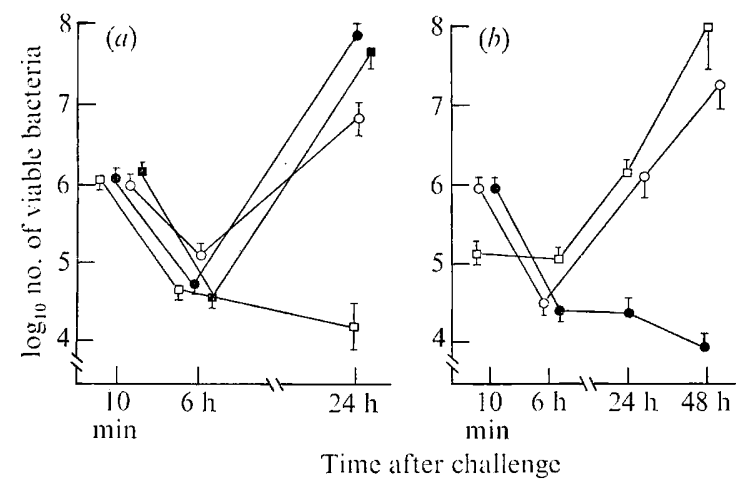

Fig. 6. Effects of (a) 900 R-irradiation and (b) carrageenan on bacterial growth in the livers of immunized mice. In $(a)$, symbols indicate: $O$, non-irradiated non-immunized controls; irradiated non-immunized mice; $\square$, non-irradiated immunized mice; $\boldsymbol{\square}$, irradiated immunized mice. In $(b)$ : $\bigcirc$, non-immunized controls; $\bullet$, immunized mice; $\square$, immunized mice treated with carrageenan. Each point and bar indicates the mean result for five animals \pm S.E.M.

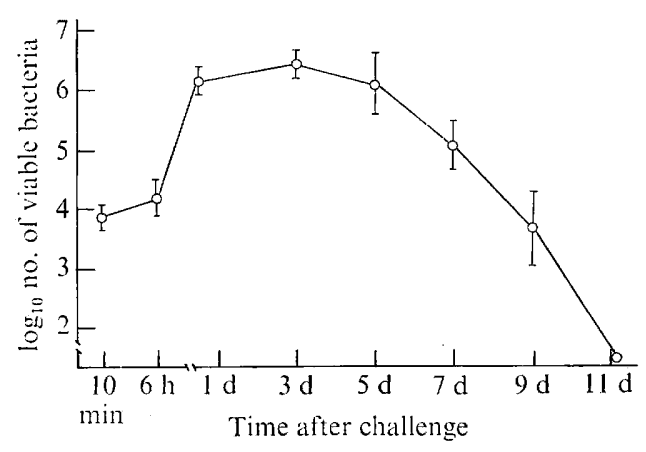

Fig. 7

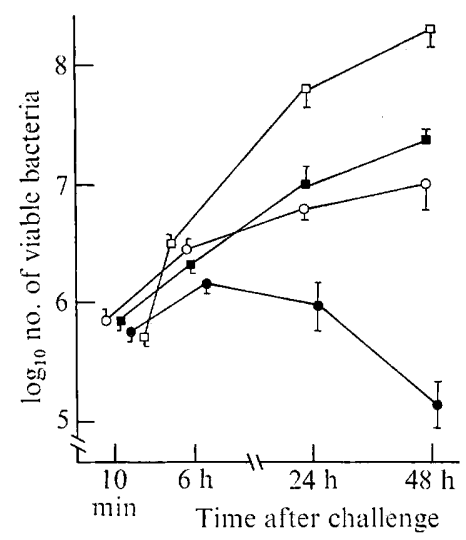

Fig. 8

Fig. 7. Time course of bacterial growth in infected thigh muscles after intramuscular inoculation of $1 \cdot 1 \times 10^{4} \mathrm{~L}$. monocytogenes. Each point and bar indicates the mean result for five animals \pm S.E.M.

Fig. 8. Effects of $900 \mathrm{R}$-irradiation, carrageenan and immunization on bacterial growth in infected thighs after intramuscular inoculation of $10^{6}$ L. monocytogenes: $\bigcirc$, control mice; $\bullet$, immunized mice; $\square$, irradiated 'mice; $\mathbf{\square}$, mice treated with carrageenan. Each point and bar indicates the mean result for five animals \pm S.E.M.

controls increased progressively until $24 \mathrm{~h}$, while the number in immunized mice continued to decrease (Fig. $5 a$ ).

When $3 \times 10^{3}$ viable bacteria were inoculated into immunized mice, bacteria in the liver decreased to reach an undetectable level within $3 \mathrm{~d}$ without proliferation (Fig. $5 b$ ).

The effects of X-irradiation and carrageenan treatment on bacterial growth in the liver of immunized mice were investigated. Immunized mice were exposed to $900 \mathrm{R}$-irradiation $3 \mathrm{~d}$ before challenge with $10^{6} \mathrm{~L}$. monocytogenes. Bacterial growth in immunized mice was modified by whole body irradiation to a pattern similar to that in irradiated, non-immunized mice (Fig. $6 a$ ). Injection of carrageenan into immunized mice $24 \mathrm{~h}$ before the challenge reduced the trapping of bacteria by $10 \mathrm{~min}$ and abolished the protective mechanism for continuous elimination in immunized mice (Fig. 6b). 


\section{Bacterial growth after intramuscular (local) infection}

The growth pattern of $L$. monocytogenes in the thigh muscle was examined after inoculation of $1 \cdot 1 \times 10^{4}$ bacteria. The number increased progressively by $24 \mathrm{~h}$ without any transient reduction at a very early stage of infection as observed in the liver (Fig. 7). A constant level of approximately $10^{6}$ bacteria was sustained from day 1 to day 5 and the number decreased thereafter.

The effects of several treatments on the local growth of bacteria at an early stage of infection were studied. A suspension containing $10^{6} \mathrm{~L}$. monocytogenes was inoculated into normal mice, irradiated mice, mice treated with carrageenan and immunized mice. In immunized mice, the number of live bacteria decreased from $6 \mathrm{~h}$ to $48 \mathrm{~h}$ with a transient increase by $6 \mathrm{~h}$. Bacterial growth in normal mice was enhanced substantially by X-irradiation. The effect of treatment with carrageenan was not so prominent on local bacterial growth (Fig. 8).

\section{DISCUSSION}

The growth pattern of $L$. monocytogenes in the liver or spleen has been widely used for the assessment of protective immunity against this facultative intracellular parasite. Tripathy \& Mackaness (1969) observed an initial fall in the bacterial count in the liver but not in the spleen, but gave no detailed analysis. From the results of the present studies, the trapping of bacteria and a decrease in number at a very early stage of infection appear to be attributable to radio-resistant phagocytes, whose functions were depleted by carrageenan. The cells responsible for protection in this first phase may be the fixed macrophages of the liver, Kupffer cells, since differentiated macrophage populations are resistant to irradiation (Kornfeld \& Greenman, 1966; Nelson, 1969; Gillette \& Lance, 1973) but sensitive to carrageenan (Catanzaro, Schwartz \& Graham, 1971). Furthermore, the efficiency of such protection in the liver was not augmented by immunization. The early protection was undetectable in the spleen after systemic infection or in the muscle after local infection. The lack of the early protection in local infection is presumably a consequence of the small number of fixed macrophages in the muscle, and its absence in the spleen may be due to some differences in the number or activity of fixed macrophages from those in the liver.

In mice exposed to irradiation or treated with carrageenan, the number of bacteria increased nearly exponentially from $6 \mathrm{~h}$. The suppression of such a fulminating bacterial growth by $72 \mathrm{~h}$ which occurs in normal mice may be ascribed to normal phagocytes, since the suppression is similar in athymic nude mice and normal littermates (Takeya et al., 1977). The cells responsible for such protection may be some population of circulating phagocytes but not the fixed macrophages in the liver, since shielding of the liver in whole body irradiation did not prevent fulminating bacterial growth by $72 \mathrm{~h}$. Such an explanation may be supported by the results of North (1970) who showed that local irradiation of the liver, with the rest of body shielded, did not enhance bacterial growth by $72 \mathrm{~h}$. It is reported that neutrophils begin to accumulate in the lesion a few hours after infection and macrophages become detectable at $48 \mathrm{~h}$ and comprise the majority of infiltrating cells at $96 \mathrm{~h}$ (North, 1970). A fulminating bacterial growth from 48 to $72 \mathrm{~h}$ was evoked by treatment with carrageenan which was reported to be cytotoxic to macrophages but not to lymphocytes (Allison, Harington \& Birbeck, 1966; Catanzaro et al., 1971). Carrageenan appears to affect macrophages preferentially, since our experiments (unpublished data) showed that carrageenan decreased the number of circulating monocytes but increased polymorphs. Blood monocytes or their precursors are radio-sensitive unlike fixed macrophages (Benacerraf et al., 1959; Volkman \& Collins, 1971). Therefore, prevention of a fulminating growth at the second phase, i.e. by $72 \mathrm{~h}$, appears to depend upon the accumulation of immature macrophages, although the contribution of polymorphs cannot be ruled out completely.

Complete elimination of $L$. monocytogenes from organs depends upon the accumulation 
of activated macrophages mediated by cellular immunity (Mackaness, 1962, 1969). Accumulation of a large number of macrophages in the lesions has been ascribed to local proliferation of fixed macrophages (North, 1969) or assembling of monocyte-derived macrophages in inflammatory sites (McGregor \& Koster, 1971).

In immunized mice, no bacterial multiplication occurred in the organs. The first phase of killing, attributable to fixed macrophages, appears to be followed by the third phase, attributable to immunologically activated macrophages. The establishment of immunity did not influence the uptake and killing of bacteria in the liver after re-challenge.

In the course of local infection, protection appears to initiate from the second phase depending upon the accumulation of free circulating phagocytes.

Thus, we divided the course of infection with $L$. monocytogenes tentatively into the first phase depending on fixed macrophages, the second phase depending on the accumulation of free macrophages and the third phase depending on the accumulation of immunologically activated macrophages.

This work was supported by Grants-in-Aid from the Ministry of Education, Science and Culture and the Ministry of Health and Welfare, Japan.

\section{REFERENCES}

Allison, A. C., Harington, J. S. \& Birbeck, M. (1966). An examination of the cytotoxic effects of silica on macrophages. Journal of Experimental Medicine 124, 141-153.

Benacerraf, B., Kivy-Rosenberg, E., Sebestyen, M. M. \& ZWEIFACH, B. W. (1959). The effect of high doses of $\mathrm{X}$-irradiation on the phagocytic, proliferative and metabolic properties of the reticuloendothelial system. Journal of Experimental Medicine 110, 49-63.

Catanzaro, P. J., Schwartz, H. J. \& Graham, R. C. (1971). Spectrum and possible mechanism of carrageenan cytotoxicity. American Journal of Pathology 64, 387-404.

Emmerling, P., Finger, H. \& BockemüHL, J. (1975). Listeria monocytogenes infection in nude mice. Infection and Immunity 12, 437-439.

Gillette, R. W. \& Lance, E. M. (1973). Kinetic studies of macrophages. IV. Effect of irradiation. Journal of the Reticuloendothelial Society 14, 18-25.

Kornfeld, L. \& Greenman, V. (1966). Effect of total body X-irradiation on peritoneal cells of mice. Radiation Research 29, 433-444.

Mackaness, G. B. (1962). Cellular resistance to infection. Journal of Experimental Medicine 116, 381-406.

MACKANESS, G. B. (1969). The influence of immunologically committed lymphoid cells on macrophage activity in vivo. Journal of Experimental Medicine 129, 973-992.
MCGregor, D. D. \& Koster, F. T. (1971). The mediator of cellular immunity. IV. Cooperation between lymphocytes and mononuclear phagocytes. Cellular Immunology 2, 317-325.

NELSON, D.S. (1969). Macrophage and Immunity. Amsterdam: North Holland Publishing Company.

NorTH, R. J. (1969). Cellular kinetics associated with the development of acquired cellular resistance. Journal of Experimental Medicine 130, 299-314.

NoRTH, R. J. (1970). The relative importance of blood monocytes and fixed macrophages to the expression of cell-mediated immunity to infection. Journal of Experimental Medicine 132, 521-534.

Takeya, K., Shimotori, S., TANiguchi, T. \& Nomoтo, K. (1977). Cellular mechanisms in the protection against infection by Listeria monocyiogenes in mice. Journal of General Microbiology 100, 373-379.

Tripathy, S. P. \& Mackaness, G. B. (1969). The effect of cytotoxic agents on the primary immune response to Listeria monocytogenes. Journal of Experimental Medicine 130, 1-16.

Volkman, A. \& Collins, F. M. (1971). The restorative effect of peritoneal macrophages on delayed hypersensitivity following ionizing radiation. Cellular Immunology 2, 552-566. 